\title{
Proceeding
}

Supplementary Issue: Spring Conferences of Sports Science. Costa Blanca Sports Science Events, 19-20 June 2020. Alicante, Spain.

\section{Youth deviance in group and prevention in educational- training contexts: Biodanza SRT as a strategy for the development of personal skills and talents}

\author{
ROBERTA ROSA ${ }^{1} \unlhd$, GIUSEPPE MADONNA ${ }^{2}$ \\ ${ }^{1}$ UUL Telematic University, Italy \\ 2University of Naples "Parthenope", Naples, Italy
}

\begin{abstract}
Youth deviance in Italy is a phenomenon that is involving an ever-increasing number of young people and, unfortunately, is contributing strongly to crime, with a corresponding increase in frequent recidivism. It is urgent to undertake actions aimed at prevention through effective intervention proposals reflecting a high educational value and a transformative value of deviant behaviour and social maladaptation, aimed at the development of psycho-social and crossmodal (body-emotional-empathetic-cognitive-relational) skills useful to counter the onset of criminal behaviour. Being a valid educational-training strategy to be implemented in compulsory schools, though actively involving experiences, Biodanza SRT focuses body and corporeity as paths of knowledge, restoring human dignity, positive identification, empowerment, consciousness, talent enhancement and awareness of oneself, of one's own abilities and skills.
\end{abstract}

Keywords: Youth deviance in group; Prevention; Biodanza SRT.

\section{Cite this article as:}

Rosa, R. \& Madonna, G. (2020). Youth deviance in group and prevention in educational-training contexts: Biodanza SRT as a strategy for the development of personal skills and talents. Journal of Human Sport and Exercise, 15(3proc), S562-S574. doi:https://doi.org/10.14198//hse.2020.15.Proc3.09

Corresponding author. IUL Telematic University, Italy.

E-mail: robertarosa68@gmail.com

Supplementary Issue: Spring Conferences of Sports Science. Costa Blanca Sports Science Events, 19-20 June 2020. Alicante, Spain.

JOURNAL OF HUMAN SPORT \& EXERCISE ISSN 1988-5202

(c) Faculty of Education. University of Alicante

doi:10.14198/jhse.2020.15.Proc3.09 


\section{INTRODUCTION}

The continuous growth of crimes committed by groups of young people, also carried out in particularly brutal ways, gives cause for concern in civil society, not only in terms of the frequency of the violence phenomena, but also because, unfortunately, they are the result of a significant and alarming discomfort among young people; the latter violate laws or established rules in a reckless and irresponsible way, through their violent behaviour.

This is an urban deviance; it is a symptom, result and expression of a collapsed society with which adolescents find themselves having to deal. Besides aspects such as broken-up, unstable or absent families (not necessarily belonging to a weak social, cultural or economic group), socio-economic disadvantages, ethnic-cultural-religious or gender alienation and marginality, crumbling houses or school facilities, run-down neighbourhoods, an overburdened school system with too many obligations and responsibilities (often out of its direct competence) and unprepared for the management of phenomena beyond its reach, we must also consider the immoderate use of technology and related services (social, chat, web) from which derives an almost total (if not total) absence of interpersonal relationships and a very serious emotional and empathetic poverty. This leads to no longer know how to recognize the other as a person but as an object, and then to the use aggression and violence only to counteract boredom, fill the time or banally appear stronger, in order to hide instead a marked inner fragility.

The increase in the proliferation of deviant behaviour in groups has no gender distinction and goes hand in hand with the transformations in society, which drive adolescents to express their unhappiness through illicit forms of relationships and communication.

Consequently, the issue of youth deviance is to be considered a rapidly growing social phenomenon which, due to the ever more frequent acts of violence and aggression, also raises concerns and fears in schools.

Although it is school itself that is put at risk of safety in the face of youth deviance in groups, it is the very selected and privileged place where primary prevention programs are carried out, in order to avoid opportunities that may drive its students towards risky behaviour (pre-school and primary school), and/or to fight deviant behaviour that could lead to real acts of crime.

The role that schools can play in the prevention of youth deviance, even within groups, is to train students to acquire the Best Practices for the respect of human dignity and the development of personal, psycho-social and crossmodal (bodily-emotional-empathetic and bodily-emotional-cognitive-relational) skills, and the ability to enhance talents by "grasping, precisely in the particular connotations that deviance comes to assume in the individual, the possible roots of the development of a talent or the ability to innovate" (Olivieri, 2017).

The natural tendency of adolescents to transgress, and therefore to lose their way, if not recognized and well managed, can be considered that fertile ground in which deviant occasions are triggered, having so much influence on young people, from which the phenomenon of youth deviance arises.

Recently, part of the educational literature has highlighted the way skills development as the opportunity to devote oneself to generative acts can be a preventive strategy for social maladjustment and desistence from crime. 
Promotion and development of skills are considered preventive strategies against social and personal maladjustment, able to facilitate a positive integration of young people at school, work and social level, insofar as they develop in them the ability to actively participate in decisions concerning their life and the solution of their problems (Olivieri, 2017).

In order to develop skills, enhance talents and contribute to young people's training, the inclusion of Biodanza SRT interventions is being proposed within the school system as a preventive strategy to social maladjustment. This is a body-mediated Social Pedagogy that, thanks to educational-experiential laboratories based on evidences of neurosciences, educational sciences and pedagogy of corporeity, and by means of the lived experience of knowledge embodiment, allow developing personal, social and emotional intelligences, preparing young people to better respond to the demands of the contemporary world.

Skills promotion and talents training is fundamental for the prevention of risky behaviour. The Biodanza system, by proposing individualized paths based on the value of the relationship as a resource, offers a constant training aimed at developing psychosocial skills (Coping Strategies, Self-efficacy, Personal Empowerment, Resilience) crossmodal skills (bodily-emotional-empathetic, bodily-emotional, cognitiverelational) and volitional skills in order to make young people be back the protagonists of their life and to be able to create/re-create it in a virtuous way.

\section{ADOLESCENT TRANSGRESSION AND DEVIANCE}

For many years now, we have been witnessing a rapid increase in youth crime resulting from deviant behaviour, characterized by a high degree of impulsiveness and recklessness, which are among the typical attitudes used by adolescents who are often both actors and victims of crimes.

Deviant behaviours, which because of their peculiarities hinder or stop the harmonious psycho-affective development, must be distinguished from the physiological tendency to transgression during adolescence, useful for the young person to redefine personally the rules internalized in childhood.

It should not be underestimated that, compared to the past, perception of transgression has changed considerably among adolescents today, and that the risk factors predicting youth deviance are increasingly linked to states of psychic-evolutionary discomfort (not necessarily due to even actual economic or family problems).

When observing the different aggressive behaviours, violent attitudes, deviant behaviours and group crimes, the key to interpret them is not only to be found in the subjective and evolutionary meaning of the transgression itself, in the personal history and in the quality of the original emotional bonds of adolescents; it lies also in the fact that we often have to deal with adolescents whose motivation or sense attached to the act accomplished is so mysterious that it is also difficult for they themselves to explain what led them to do it.

Adolescence is an evolutionary phase, since both because the risk that psychopathological aspects may emerge is extremely high, which can be characterized by a Personality Disorder (Borderline, Narcissistic, Antisocial), and because of the implementation of mechanisms from which deviant behaviours may arise.

The role of the adult is crucial and can be ambivalent with respect to his/her ability to both containing or facilitating the risk of a deviant evolution in the adolescent. Knowing how to grasp significant aspects of a 
potential exposure for the adolescent to risk behaviours is of fundamental importance for an early and effective intervention in the management of behavioural trends, which, if not contained, can constitute a real delinquent pathology in adulthood.

Adolescence is the evolutionary stage that mostly challenges the psychological, sexual, relational and emotional balance with oneself, with others (especially adults) and with the environment, thus making young people more vulnerable and weaker. It is precisely in this phase of growth that adequate support from the family and an integrated training system should be provided ad be effective, so as to prevent young people from becoming protagonists of a risky social reality and from being involved in deviant future actions.

Youth deviance includes both criminal behaviour punishable by law and risky behaviour for it exposes a person to conditions that could compromise his/her development.

The development of antisocial and criminal behaviour by young people is typically associated with failures in the expected functions of the conventional socialization structures, both within the family, which is the space of primary socialization, and at school, the structure responsible for secondary socialization (Olivieri, 2017).

\section{YOUTH DEVIANCE IN GROUP: GENESIS AND EVOLUTIONARY ASPECTS}

In order to implement useful and functional intervention policies, it is important to have a clear picture of the situation; therefore, it needs to make considerations and reflections about the social risk factors related to youth deviance and, at the same time, to bear in mind that deviant behaviour unites groups of adolescents with very different problems.

In Italy, it is possible to observe different types of deviant or criminal youth behaviour (Mastropasqua, Pagliaroli, Totaro, 2008):

- Within young people without problems, belonging to the middle class, sometimes highly educated; they are the expression of the phenomenon of "the malaise of well-being" (well-being which is almost exclusively material, linked to the possession of goods), in which we can observe the inability to recognize the other as a subject, even if different from oneself, in "an existential and relational void that generates malaise and destructiveness".

- Within young people with economic and social problems.

- Within young people who present forms of deviance linked to situations of economic, relational and social disadvantage, combined with that derived from the marginality of urban spaces and the presence of "suburban children".

- In the new types of problems, expressions of a "deviance/symptom". The discomfort of adolescents reflects the image of a society that generally shows forms of anthropological degeneration, expressed in an unusual increase of communicative aggressiveness, of hyperreactivity as an expression of an inner conflict that is closely related to the constant change and instability of the family, of the family and social roles of the members in the family nucleus, of schoolmates, of peer or associative groups.

Even if an ever-increasing problematic situation of young people is manifested at any ethnic group, a further element that should not be underestimated is the increasing presence of non-EU populations in Italy. Despite the commitment of society and schools to welcoming foreigners and to promoting inclusion and integration programs/strategies, it is not always easy for a child or an adolescent to grow up in a foreign country, and 
therefore they could be more exposed to the risk of adopting deviant behaviour or joining crime-oriented groups.

An equally decisive risk factor is the influence of the mass media and technological communication (internet, video games, chat, mobile phones, the many TV channels, and so on) which, with the introduction of the virtual presence of the other, is changing the cognitive and affective representation of the relational space, adding complexity to the creation of socio-educational proximities.

Belonging to an always hyper-connected digital generation that spends entire days on the net, up to its definitive disconnection with reality, to the simulation of parallel lives, nicknames and avatars, is the cause of the more and more widespread discomfort among children.

However, the exponential development of skills in the field of technological communication is associated with the increased dangerous emotional-affective illiteracy, leading to the lack of those vital codes useful both to recognize the "presence of the other" and to manage emotions and affections, by strongly exposing young people to the de-humanization of the relational universe.

Everything happens online: you get to know someone, fall in love and flirt with him/her, you can get undressed, you start relationships and then break up ... you are absorbed in surrogates of affectivity that generate isolation and marginalization, and from this confusion of values and identities many of the deviant or violent behaviours in adolescents are also often reproduced by imitation, contagion or emulation. Websites that praise transgressive, violent, criminal behaviours continue to feed the desire of young people to feel like protagonists by re-proposing the same actions in real life, without being aware of them or feeling fear, believing that they are invincible and won't be unpunished, being sue that there is nothing wrong or abnormal as it is just a game.

The aggressiveness that emerges in young people with attitudes of prevarication and denigration, defined as bullying, is another new sign of discomfort confirming a violence caused by boredom, in order to express frustrations suffered or to arouse attention (Vettorato, 2010). Bullying is characterized by violent and intimidating actions carried out on a victim by a bully, or a group of bullies, through verbal harassment, physical aggression and persecution, generally carried out in a school environment. Today, technology allows bullies to break into victims' homes, and materialize at any time in their lives, haunting them with offensive messages, images, videos sent via smartphone or posted on websites via the Internet. This phenomenon, being developed on the net, is called cyberbullying; it is a set of aggressive and intentional actions, carried out by a single person or a group, using electronic means (text or multimedia messages, photos, videos, emails, chat rooms, websites, phone calls) with the aim of causing damage to a peer unable to defend himself/herself.

The high rates of deviance and violence are strongly affected by the social changes which are occurring all over the world: a growing youth population, issues related to social inequality such as unrestrained urbanization and fragmentation of spaces.

The development of antisocial and criminal behaviour by young people is typically associated with failures in the expected functions of the conventional socialization structures, both in the family, which is the space of primary socialization, and at school, the structure responsible for secondary socialization (Olivieri, 2017). 
Weak families with absent or non-existent parenting styles are important factors in creating situations of discomfort and deviance, just like school experience is no stranger to being responsible for the marginalization and deviance processes. In the adolescent's growth path, moreover, the experience with peers also becomes fundamental and decisive for the development of his/her identity, since this group/environment can become a place of potential production of discomfort and deviance (or vice versa), becoming a place of compensation in which to deal with deficiencies in affective relationships caused by the adults of reference or by other significant figures. A not too indirect risk factor is also linked to the quality of the environment, which, although informally, tends to educate. Degraded urban environments favour the concentration of situations of social marginalization, the nesting of gangs, illegal trafficking, drug dealing and proliferation of criminal organizations. Nevertheless, the relationship between adolescents and the city is problematic even where there are no clear signs of degradation, as the modern city is now poor in healthy places for leisure and gathering, having become a reality with no real relationships among people but with dangerous social breakdown. Today's city denies young people all those spaces in which they can express themselves positively at creative level (Vettorato, 2010).

The result of all these negative factors leads youth groups to express themselves in a dysfunctional way, in order to manifest an intrinsic need of adolescents to experience themselves and achieve their autonomy. (Vettorato, 2010).

Repressing adolescent traits leads young people to express, as soon as they can and very loudly, what otherwise has not been or is not being listened to. Thus group transgression results in a need for attention manifested through acts of protest, vandalism, graffiti, stained city walls, night time noises, destruction of civilization symbols degenerating into "misdeeds such as throwing rocks off bridges (which become potentially deadly missiles), attacking one's own families, destroying properties, car thefts, drugs dealing, and other 'bloody' acts of violence". It is necessary to distinguish between deviant behaviour and truly criminal conduct. The former is linked to the structure of the personality and of the socio-cultural environment, while the latter is the result of more or less fortuitous factors, codified by law (Olivieri, 2017).

Among the many personality disorders affecting young offenders' personality we can find recklessness, lack of sense of responsibility and inhibition, lack of guilt or regret, emotional poverty, lack of goals and inadequate ability to develop relationships; all characteristics typically associated with psychopathy and antisocial personality (Olivieri, 2017). Consequently, policies must be implemented to prevent deviance at an early stage, intervening in the social, economic and cultural conditions that can favour it through early and targeted interventions; they are the most likely to succeed, even if they are more costly.

It would be desirable to reduce re-educational or repairing interventions as much as possible, because they are carried out when a crime or transgression has been already committed, and therefore when the damage is already done. Intervening belatedly is better than letting someone go through all the stages of a criminal path, although it would be better not to have it as an option at all. In fact, prevention is the best therapy! (Vettorato, 2010).

\section{PREVENTION OF YOUTH DEVIANCE IN GROUPS AND IN EDUCATIONAL TRAINING CONTESTS}

In its broader meaning, training shapes the action systems. Therefore, training aimed at the prevention of deviance is understood as the action that shapes bio-psycho-social action systems. 
Thus, it can play an important role in mitigating or preventing the opportunities for negative deviance, which have so much influence on young people, by supporting high levels of training aimed at young people so that they can achieve their autonomy, make the most of their talents and be the protagonists of their own lives, thus helping create a better society.

It should be kept in mind that, while on the one hand there is the inability of some students to perceive what school has to offer them, on the other hand there is a school that often cannot or are inadequate to offer enjoyable opportunities for action and involvement, creating an exodus of young people towards alternative anti-social structures such as the delinquency action system, which seems to represent an attractive alternative to be or feel involved in when few other options are available.

School cannot and should not give in or adapt to failure but should understand what are the best strategies to implement in its social context so as to address the problems of deviance and youth delinquency in groups at school.

According to the research outcomes of the various international studies, the promotion of skills and the training of talents is closely linked to the prevention of risky behaviour.

The expectation of a possible turnabout and a change in deviant behaviour has increased considerably in recent years, as a result of the observation that deviant or criminal behaviour profiles can change over time. This occurs because subjects are surrounded by positive environmental factors, capable of stimulating them to reach a turning point such as to produce a real change in their life, and because of their individual and social characteristics, thus by leveraging their potentialities and their ability to implement coping and resilience strategies (namely those protection factors that individuals are able to use to limit or counteract risk factors).

Skills promotion and development are considered preventive strategies against social and personal maladaptation, able to facilitate the positive integration of young people at school, work and social level, insofar as they manage to develop in them the ability to actively participate in decisions concerning their life and the solution of their problems (Olivieri, 2017).

In order to reflect on how to deal with young people's training, it could be useful to consider that approaches to prevention have a positive and effective influence on the management of violence among young people only when the activities proposed successfully involve and meet the needs of the groups most at risk and of all young people, thus also influencing their relationships and the environments in which they grow up and learn.

It is important to invest in the lives of all young people from an early age, by supporting and improving pathways based on the training of their psycho-social and crossmodal skills as a preventive strategy against youth social maladjustment, various forms of delinquency and, at the same time, the risk of being involved in criminal justice.

Such a training is based on experiences lived in a positive and emotionally motivating context, in order to make it easier for adolescents to acquire a good level of self-efficacy (feeling able to recognize their skills, value and make the best use of them, feeling constantly oriented towards the goal or overcoming a problem, beyond the difficulties and possible failures in the process), and a good level of empowerment (having learned to recognize their personal resources and to rely on them). 
Another objective of a training aimed at preventing deviance and delinquency is to enhance talent by leveraging, precisely in young people or particularly in those ones who adopt deviant behaviour, their ability to express a talent, even if in an illegal way.

It should not be underestimated - but rather well assessed - that talent, which in our society becomes an entrepreneurial skill, can be used both in productive and destructive sectors (crime and delinquency). It goes without saying that the selection of the sector in which to invest one's own talent will depend on the advantages and rewards offered, which are not always legal, putting the lives of young people at risk if they are not adequately equipped to deal with critical situations as they lack the right tools, strategies and resources.

While resilience factors are partially innate, protective factors are subsequently acquired and correspond to the talents that need to be nurtured; where necessary, they need to be adjusted, in order to meet the needs of the person and of society (Olivieri, 2018).

Possessing the street smarts involves thinking in a sophisticated way, just as required for specific professional figures. Talented young people who find themselves in degraded environments often learn to express their talents in terms of street survival efforts, by joining a gang and participating in its criminal activity, implementing a form of practical intelligence that is often unrecognized and disregarded in deviance-related environments, but which takes on great value when attributed to environments of excellence.

This kind of intelligence is expressed in young people through rebellion and provocation, two trends that can also be used positively. This comes through experiences and transformative practices able to promote the so-called flourishing: this means: the flourishing of knowing how to live a range of functional possibilities characterized by virtues, productivity, growth and resilience (such as motor activities, sports, arts and social commitment); it is possible for young people to recognize their roots and the meaning they attribute to their rebellion and provocation, in order to help them understand how to channel and gradually bring them towards a potential beneficial socio-cultural change. The aim is to promote and emphasize personal resources (instead of deficits and diseases) by adopting bio-psycho-social approaches aimed at facilitating optimal functioning, satisfaction, positive affectivity and vital impetus.

Each individual, and especially young people with deviant or violent behaviour, should be guided to understand what he or she is actually capable of doing and being, and what he or she is capable of imagining and wishing, in order to make choices (Rosa, 2019).

During the evolutionary period, research and discovery are primary attitudes and activities for the growth and development of one's own identity. Therefore, in a training process, it is important to offer young people different opportunities for "discovery", so that they can explore themselves and go in search of their own daemon (their real self) by exploring the personal pleasure aspect linked to positive feelings and emotions (Hedonic philosophy), and by living experiences that respond to personal potentials representing the best one is able to become (Eudemonic philosophy).

When subjects are defined as delinquent or criminal (or when telling them things like "you are a bad child"), they get labelled and imprisoned in a stigma for which society considers them as bad or dangerous by default, but this label gets then embedded in their identity, leading them to behave in accordance with this assimilation and by showing this feature to the others. 
The objective of identity training is identified in the discovery of the nature of one's own daemon and includes: discovering one's own personal potentialities; choosing one's own life goals; finding the right opportunities to turn these potentialities and goals into action.

Our identities determine where we can go, where we will be allowed access or where we will be accepted, and where we risk feeling threatened (Olivieri, 2018).

In the training process, the positive identification process and the development of personal potentialities and talents to be used in life must be facilitated.

Consequently, starting from kindergarten and primary school, prevention activities should be mainly targeted and oriented towards the learning-to-be (learning to recognize and manage emotions, experience empathy, communicate naturally by learning to solve interpersonal conflicts in a non-violent way), while in secondary schools the aim should be the learning-to-live-together (developing one's own ability to understand the thoughts and feelings of others, learning to manage anger, experiencing confidence and optimism towards, others and the future, and becoming positive leaders).

However, school alone risks again being lost or failed, because deviance prevention is possible provided that there is an integrated system between family and social (and judicial) environment paying attention to the signs of distress, and promoting the acquisition of resources, potentialities, skills and opportunities for wellbeing, in addition to all the necessary skills to cope with the growth and difficulties inherent in daily life.

The primary, secondary and tertiary prevention of youth delinquency must therefore include the development of personal skills and talents, which are alternatives to criminal talent and can be an excellent preventive strategy against the risk of social maladjustment.

Therefore, explicit attention must be paid to investing in educational and training practices, capable of generating tangible changes (especially in the long term) which promote the development of talents and personal and social success. In addition, they should concretely contribute to a responsible growth of subjects by facilitating the "reprogramming" of a life path, having it proved deviant and deviated up to then (Rosa, 2019).

Training personal psycho-social, emotional and crossmodal skills is important at all ages, since it affects the reduction of aggressive and violent behaviour, the sense of social awareness and the humanization process.

\section{CORPOREITY AND MOTOR SKILLS IN THE EMBODIED THEORY PERSPECTIVE}

Motor activities, movement and corporeity promote empowerment, change, opportunities, learning, orientation, problem solving, sharing, participation, dialogue, exchange, confrontation, rediscovery of oneself and one's own life project, playing an important role in providing positive experiences useful to improve one's own quality of life.

For some time now, neurocognitive and psycho-pedagogical sciences have focused on the role of the body and corporeity in the cognitive and identity building/development process.

From the embodied theory construct (Varela, Thompson, Rosch, 1991) and from the embodied cognition research works, it is clear that cognitive processes are deeply rooted in the body (sense-motor-emotional 
system), in the action, and are strongly interconnected with the environment (intersubjectivity), in which the human being lives, acts and interacts (Varela, Thompson, Rosch, 1992).

All human experiences are necessarily mediated by the body. Already from prenatal age, it is the body that allows the human being to meet the world, a necessary condition to "embody experiences" and develop knowledge of oneself, others and the world.

The body as an action device to experience the world is indispensable for the attribution of meanings. In fact, the didactic use of the body represents an object of scientific investigation both for neurosciences and for bio-educational sciences for the promotion and re-evaluation of its potentialities as physical, motor, nonverbal, proxemic, emotional, communicative-affective, and socio-relational factors.

By assuming an important transversal potential, corporeity and motor skills are to be understood as a necessary condition for the structuring of knowledge and as a precious key to inclusive, ethical and pro-social behaviour.

Consequently, it follows that the enhancement of the body and the emotions for preventing youth deviance in groups is an educational-training strategy able to stimulate the development of multiple intelligences and emotional intelligence, so as to enhance the existential creativity that teaches us to exploit critical issues as opportunities for growth.

For effective interventions with lasting effects over time, particular attention should be paid to innovative teaching methods that focus on the body as a medium through which, thanks also to a learning environment enriched with positive eco-factors, it is possible to create useful experiences to develop personal resources stimulating the reorganization of self-knowledge.

Therefore, the educational project models must necessarily refer to a holistic and systemic approach that promotes the participation of all actors, the ability to empathize, to be protagonists of one's own life while respecting the value and dignity of others in order to trigger a real change.

Motor activity turns out to be an essential prerequisite from which to undertake effective educational actions, since it provides opportunities enabling the development not only of motor skills, but also of those social, relational, affective and cognitive ones; in addition, it generates a safer and more positive self-image and the awareness of being the main agent that actively operates in the context in which one lives.

Corporeity involves physical-motor, cognitive, affective-emotional, psychosocial, behavioural, relational and cultural factors, responding to the promotion and maintenance of people's health according to a bio-psychosocial perspective, contributing to the development of policies in favour of communities (Rosa, De Vita, 2019).

\section{BIODANZA SRT: STRATEGY FOR THE DEVELOPMENT OF PERSONAL SKILLS AND TALENTS}

The Biodanza SRT System is a body-mediated Social Pedagogy that, through the learning-by-doing approach, proposes experiential group laboratories, using (in a specific Gestalt) dance/movement, music and group meeting situations as methodological resources to induce vivencias; the latter can be defined as "integrating experiences lived with great intensity in the here-now" (Toro Araneda, 2000). 
The Biodanza methodology facilitates the contact with oneself and one's own emotions by regaining contact with others and with the context. By awakening sensitivity, empathy, self-confidence, self-esteem, selfefficacy and listening skills, it strengthens the empowerment of a positive identity, the development of one's own strengths and the enhancement of one' s own talents.

In facilitating self-rediscovery from within, Biodanza encourages the research and knowledge about oneself, the re-structuring of a positive self-identity, the desire to react and move on after difficult situations, the rediscovery of the value of the self, the sense of self-efficacy and human dignity.

The introduction of Biodanza SRT as an educational tool in school and Existential Re-education contexts is now becoming an increasingly widespread practice in Italy and abroad.

Scientific evidence has shown that continuous Biodanza activity in school age clearly improves students' emotional intelligence and self-esteem, (López, Fierro-Suero, Fernández-Ozcorta, Sáenz-López Buñuel, 2018); the cortisol levels in the body decrease by reducing stress, useful to implement the recognition of emotions, concentration and enhancement of social skills (Stueck, Villegas, Lahn, Bauer, Tofts, Sack, 2016).

A study focused on Biodanza SRT interventions proposed to convicted minors highlighted a qualitative significance of the experience lived by prisoners in all the estimated aspects, i.e. those of cognitivebehavioural, emotional, motivational and relational nature, and those which facilitated the adoption of socially accepted behaviours that underpin their reintegration into civil society (Rosa, 2019).

Biodanza SRT turns out to be an important prevention strategy for emotional distress, constituting a real work of emotional literacy. The process of affective-emotional education is based on the strengthening of personal factors and skills, capable of stimulating multiple intelligences and promoting balanced and functional emotional reactions (Rosa, De Vita, 2019).

Biodanza SRT contributes positively to developing:

1) Social skills, empathy and inclusion, by fostering positive relationships with others, pro-social, cooperation and inclusion behaviour.

2) Emotional literacy and empowerment, by adopting attitudes and behaviours which are adaptive and functional to the achievement of psycho-physical well-being and increasing the sense of individual responsibility.

3) Emotional-affective, socio-relational and metacognitive skills, which are also decisive for the development of learning processes and for school profit.

As a result, integrating Biodanza SRT into the school environment contributes to enhancing the child's and young person's cross skills at school age, closely related to cognitive development, communication skills, interpersonal skills and social interaction, and to collaboration and cooperation with others.

The transformative, educational and didactic potential of Biodanza SRT is based on body-mediated training processes, capable of triggering an existential change that is strictly linked to the enhancement of social skills, crossmodal skills and talents.

\section{CONCLUSIONS}

Investing in building personal skills and valuing talents as a preventive strategy to youth deviance in groups 
means thinking and considering the young people involved as a resource for society, by exalting their expressed potentialities rather than their hypothetical inabilities.

Favouring the development of soft skills and potentialities and valuing personal talents means stimulating the personality function in all its various aspects, making the subject interact continuously with the environment.

It is through talent education that the training process strongly contributes to building up a sustainable society.

Biodanza SRT acts on the development of people's emotional, relational and social skills, and is an excellent educational-training strategy to be applied in all school contexts, at all levels, as a useful strategy for the prevention of youth deviance in groups.

The pedagogical and educational effectiveness of Biodanza SRT leads us to hope for its inclusion in compulsory school contexts, by means of targeted and long-lasting interventions.

Biodanza SRT as a path of Psycho-Motor-Affective-Relational Coaching is a valid specific educational intervention to be used in the prevention of youth who are at risk, deviant or detained (in different areas and at different ages), because its characteristics meet the criteria of Transversality, Interdisciplinarity, Laboratories, and Methodological Innovation (Rosa, 2019).

\section{REFERENCES}

López J.R.H., Fierro-Suero S., Fernández-Ozcorta E.J., Sáenz-López Buñuel P. (2018). Efectos de un programa de biodanza en relación a parámetros físicos y psicológicos en Educación Primaria. Revista de Ciencias del Deporte , V. 14 (1).

Mastropasqua I., Pagliaroli T., Totaro M.S. (2008). I numeri pensati. $1^{\circ}$ Rapporto sulla devianza minorile in Italia, Gangemi Editor. Rome.

Olivieri D. (2018). Aspetti evolutivi della devianza: introduzione alla formazione dei talenti quale possibile strategia di prevenzione della delinquenza giovanile. in Devianza e Adolescenza. Atti di Convegno Cariati (CS), 9 giugno 2017 - Rubettino Editor. Soveria Mannelli (CS).

Olivieri D. (2017). Trasgressione giovanile, educazione e formazione dei talenti: promuovere la devianza positiva per prevenire la devianza negativa. Youthful transgression, education and training of talents: Promoting positive deviance to prevent negative deviance. Formazione \& Insegnamento XV - 2 . Pensa MultiMedia Editor.

Rosa R. (2019). Corporeità e Ri-Educabilità nel Sistema Penitenziario, in Inclusive Didactics, Methodology and Sports, 16 - Filo Refe, January 2019.

Rosa R., De Vita T.. (2019). Psycho-pedagogy of corporeality: a health and socio-educational resource in the re-educability of prisoners. in: Studi e Strumenti per una Didattica Inclusiva - V.3, N. 3, november - Italian Journal of Education to Health, Sport and Inclusive Didactics.

Stueck M., Villegas A., Lahn F., Bauer K., Tofts P., Sack U., (2016). Biodanza for kindergarten children (TANZPRO-Biodanza): reporting on changes of cortisol levels and emotion recognition. Body, Movement and Dance in Psychoterapy. An International Journal for Theory,Research and Practice Vollume 11 - Issue. https://doi.org/10.1080/17432979.2015.1124923

Toro Araneda, R. (2000). Biodanza. Musica, movimento, comunicazione espressiva per lo sviluppo armonico della personalità. Red: Cornaredo (Mi).

Varela F.; Thompson, E.; Rosch, E. (1992). The Embodied Mind: Cognitive Science and Human Experience. Cambridge, MA: The MIT Press. 
Vettorato G. (2010). La devianza giovanile in Italia negli ultimi 20 anni. In Vettorato G. - F. Gentili, Educare in un mondo che cambia, Rome, SCS, 15-34.

\section{(c) (1) (9)}

This work is licensed under a Attribution-NonCommercial-NoDerivatives 4.0 International (CC BY-NC-ND 4.0). 